\title{
Concomitant of hodgkin lymphoma and papillary thyroid carcinoma
}

\author{
Bdioui Ahlem1*, Mhammedi Nozha1, Ben N Marwa2 and Mokni Moncef1 \\ ${ }^{1}$ Department of Pathology, Farhat Hached Hospital of Sousse, Tunisia \\ ${ }^{2}$ Department of ENT, Farhat Hached Hospital of Sousse, Tunisia
}

\begin{abstract}
Patients with primary multiple malignancies are progressively increasing due to the advances in the diagnostic techniques. We report a case of 51 years old women, with no medical history; referred to the ENT department, complaining of cervical lymph node enlargement. Physical examination was unremarkable other than left cervical lymphadenopathy and the lab investigations were within normal limits. Biopsy was performed; showed sclerosis nodular classic Hodgkin lymphoma. The assessment of extension, CT scan showed cervical adenopathy and left lobe thyroid nodule, which was removed, the nodule was diagnosed as papillary carcinoma. The concomitance of both malignancies is very rare, particularly with no history of radiation which made this case an interesting for further studying.
\end{abstract}

\section{Introduction}

Patients with multiple primary malignancies are progressively increasing. Some studies have reported the association of thyroid papillary carcinoma (TPC) with lymphoma, mainly Hodgkin's lymphoma (HL), treated with radiotherapy [1]. But less than 10 cases have illustrated the concomitant of these two tumours with no history of radiotherapy. Therapeutically, a multi-disciplinary and patientoriented approach should be considered [2].

The case in this study illustrates an example of the rare two synchronous cancers of which one was fortuitously discovered.

\section{Case report}

We report a case of 51 years old woman, with no medical history, in particular with no history of radiation. The patient was nonsmoker, denied alcohol consumption and she was admitted to the ENT department complaining of cervical lymph node enlargement. Physical examination was unremarkable other than left cervical lymphadenopathy. Cervical ultrasound revealed large bilateral, multiple conglomerated lymphadenopathies in the submandibular, cervical, and supraclavicular districts.

Laboratory tests showed normal hemogram, biochemistry, and thyroid function results. Biopsy was performed; showed sclerosis nodular classic Hodgkin lymphoma (Figure 1) and the atypical cells were positive for CD30 and CD15 in immunohistostaining (Figure 2).

In the assessment of extension, the CT scan was performed, showing that the cervical adenopathies was associated to the left lobe thyroid nodule. A lobectomy was performed and the microscopical examination of the nodule diagnosed as papillary carcinoma of classic variant (Figure 3), without vascular or lymphatic embolization.

Complement of thyroidectomy was performed with preserving the inferior and superior laryngeal nerve and the four parathyroids, while the cervical lymphadenectomy revealed metastases of papillary carcinoma in 5 out of 8 lymph nodes; three of them was infiltrated by hodgkin's lymphoma (Figure 4).

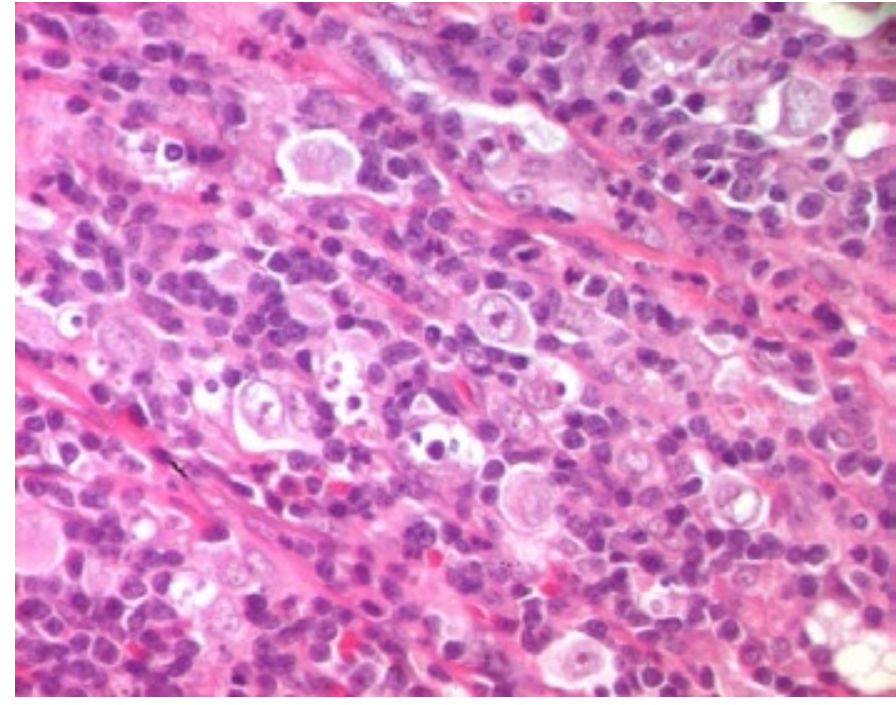

Figure 1. Lymph node infiltration by Hodgkin Lymphoma (HE x400)

Patient was referred to haematology department to undergo treatment for Hodgkin lymphoma, and to nuclear medicine for radioiodine therapy.

\section{Discussion and conclusion}

Obviously, the increasing surveillance by improving exploration techniques, have allowed the detection of more papillary carcinoma,

${ }^{*}$ Correspondence to: Bdioui Ahlem, Department of Pathology, Farhat Hached Hospital of Sousse, Tunisia, Tel: 0021652422384; E-mail: ahlembdioui@hotmail.com

Key words: multiple primary malignancies, Hodgkin's lymphoma, synchronous cancers, cervical lymph node

Received: February 10, 2020; Accepted: February 24, 2020; Published: February 26,2020 


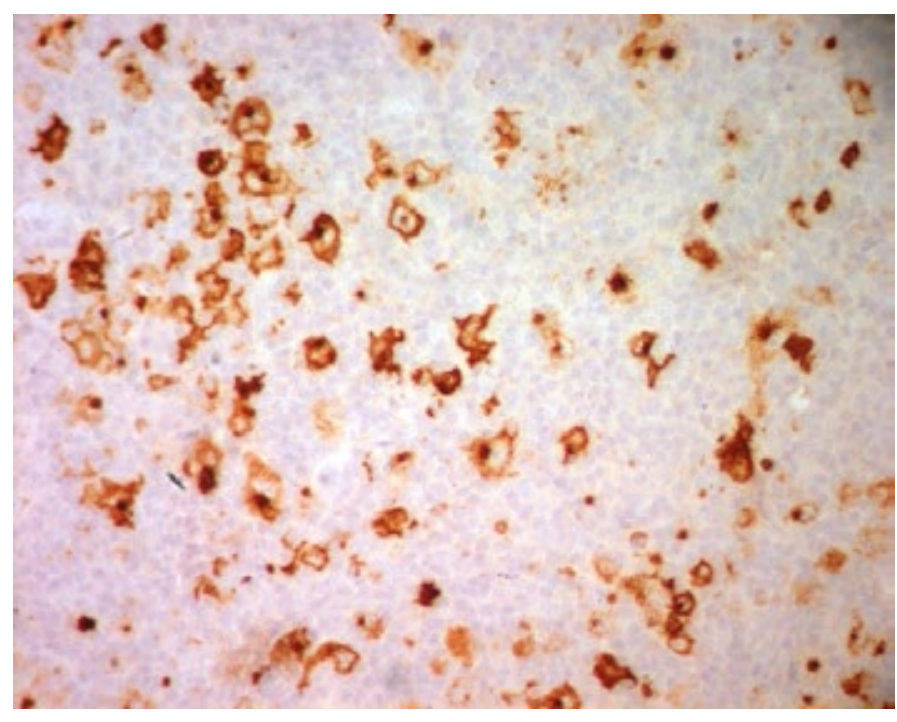

Figure 2. Hodgkin cells expression of CD15 (IHC x 400)

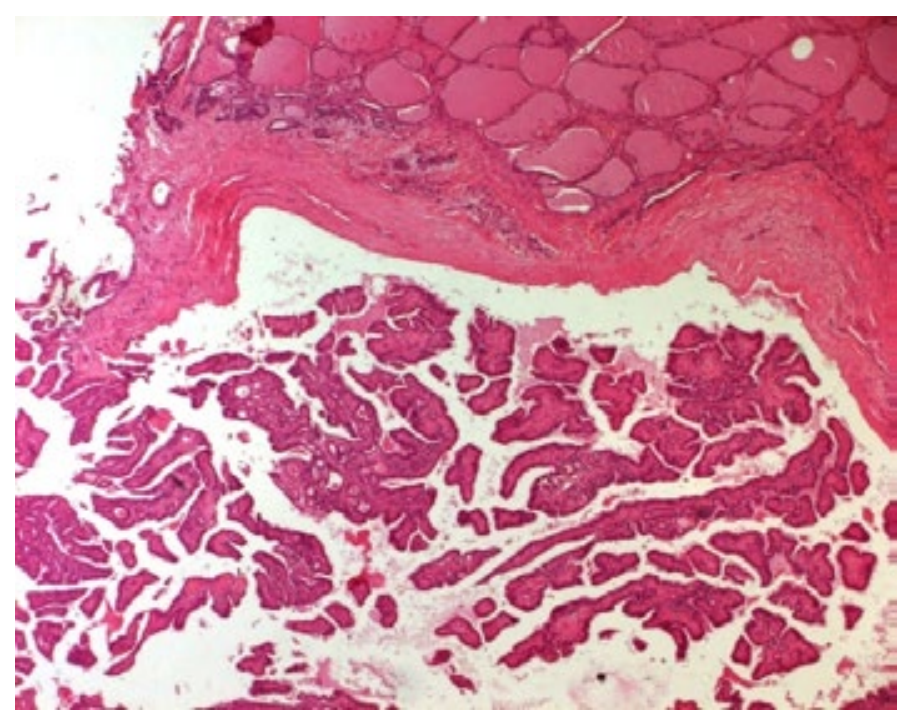

Figure 3. Papillary thyroid carcinoma (HE x 40)

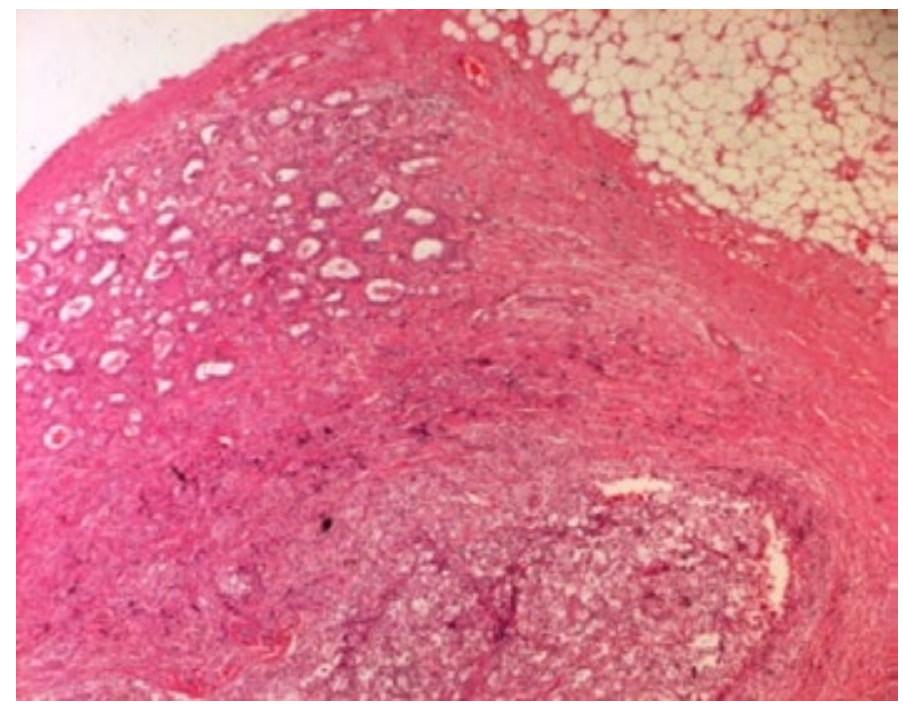

Figure 4. Double infiltration of lymph by papillary thyroid carcinoma and Hodgkin lymphoma even at an early stage. This explains the surge in the prevalence of thyroid papillary carcinomas (TPC) on one hand and the detection of many concomitant cancers on the other hand [3,4]. In addition, according to autopsy data, the TPC is more frequent than previously thought. Often indolent, it is found incidentally in 5 to $35 \%$ of autopsy and surgical removed glands [5].

Simultaneous thyroid carcinomas and other head and neck carcinomas are mainly explained by common environmental risk factors which initiating both primary cancers. Some studies have reported the association of thyroid papillary carcinoma (TPC) with lymphoma essentially Hodgkin's lymphoma (HL) treated with radiotherapy [1]. But less than 10 cases have illustrated the concomitant of these two tumours with no history of radiotherapy [6].

TPC and Hodgkin Lymphoma do not share the same factors. A genetic origin remains possible but so far, no mutation has been revealed linking these two cancers. Many mutations have been involved in the development of these tumors separately. For example, the BRAF mutation described in the TPC and numerous non-hodgkin's lymphomas has never been described in the HL [7]. Thus, the existence of these entities and these rare events could be used for molecular diagnosis of a common oncogene origin.

As regards the therapeutic approach, a total thyroidectomy was performed for our patient followed by chemotherapy mainly targeting the HL.

It has been described that metachronous TPC and HL has a poor survival. But the scarcity of synchronous forms does not make it possible to evaluate their real survival impact [8].

\section{References}

1. Weshler Z, Krasnokuki D, Peshin Y, Biran S (1978) Thyroid Carcinoma Induced by Irradiation for Hodgkin's Disease: Report of a Case. Acta Radiol Oncol Radiat Phys Biol 17: 383-386. [Crossref]

2. Aşık M, Ozkul F, Toman H, Durmuş A, Anaforoğlu I, et al. (2013) Co-occurrence of Papillary and Follicular Thyroid Carcinoma in a Patient with Hodgkin's Disease. Turk J Haematol 30: 209-210. [Crossref]

3. Koutsopoulos AV, Dambaki KI, Datseris G, Giannikaki E, Froudarakis M, et al. (2005) A novel combination of multiple primary carcinomas: urinary bladder transitional cell carcinoma, prostate adenocarcinoma and small cell lung carcinoma- report of a case and review of the literature. World J Surg Oncol 3: 51. [Crossref]

4. Rizkallah JJ, Jambart SS, Maalouli GD (2014) Synchronous diagnosis of a hodgkin lymphoma and a papillary carcinoma of the thyroid. Case Reports Inter Med 1: 2 .

5. DeLellis RA (2004) Pathology and Genetics of Tumours of Endocrine Organs. WHO.

6. Krishnatreya M, Rahman T, Kataki AC, Lahkar K (2015) Synchronous primary cancers in the head and neck region and upper aero digestive tract: Role of triple endoscopy. Indian J Cancer 52: 53-56. [Crossref]

7. Hussain MR, Baig M, Mohamoud HS, Ulhaq Z, Hoessli DC, et al. (2015) BRAF gene: From human cancers to developmental syndromes. Saudi J Biol Sci 22: 359-373. [Crossref]

8. Lang BH, Lo CY, Wong IO, Cowling BJ (2010) Impact of second primary malignancy on outcomes of differentiated thyroid carcinoma. Surgery 148: 1191-1197. [Crossref]

Copyright: (C2020 Ahlem B. This is an open-access article distributed under the terms of the Creative Commons Attribution License, which permits unrestricted use, distribution, and reproduction in any medium, provided the original author and source are credited. 